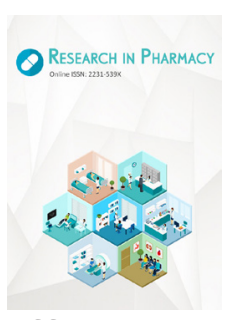

ISSN: $2231-539 X$
Received: May 08, 2020 Accepted: June 21, 2020 Published: June 28, 2020

*Corresponding Author: Unni Jayaram E-mail: jayaramkvt@gmail. com

\section{Patient's Perception of Community Pharmacist in North Malabar region of Kerala, India: A questionnaire based study}

\author{
Unni Jayaram ${ }^{a *}$, Mohamed Saleem T K ${ }^{\mathrm{b}}$, Mohamed Musthafa N K ${ }^{\mathrm{b}}$, Farzana P $\mathbf{M}^{\mathrm{b}}$ \\ ${ }^{a}$ Centre for Basic Science Research and Bioethics, Kerala University of Health Sciences, Medical College (P.O.), \\ Thrissur 680596, Kerala, India, 'Department of Pharmacy Practice, Al Shifa College of Pharmacy, Poonthavanam \\ (P.O.), Kizhattur, Perinthalmanna 679325, Kerala, India
}

\begin{abstract}
Pharmacists as vital healthcare professionals play significant role in effective medication management and their use among the patients. However the perception of community pharmacist among the public needs to be assessed for effective role and further patient care. This questionnaire based study was aimed to identify the perception of patients towards the community pharmacist in north Malabar region of Kerala, India. The questionnaire consisted of 16 questions with sections evaluating the demographic details (age, sex, marital status, education level \& occupation) and the perception of patients towards the community pharmacist. The results were prepared based upon the responses obtained from 110 patients. The study respondents consisted of 51 (46.36\%) adults (18-59 years) and $59(53.63 \%)$ geriatrics (above 60 years). Based on their education level, 9 (8.18\%), 35 (31.81\%) and $66(60 \%)$ participants were illiterate, secondary school and graduate holders respectively. The respondents of the study informed that the pharmacist enquired about their past medication history $(58,52.73 \%)$, any allergic reactions $(21,19.1 \%)$ and use of any herbal medication $(31$, $28.18 \%$ ) prior to the dispensing process. The patients also responded that proper advice regarding dosage (90\%), side effects $(25 \%)$, storage (12\%), healthy eating \& exercise $(10 \%)$ were also provided by the concerned pharmacist. As a matter of fact, 91 out of 110 patients thought the pharmacist service were good, 17 thought they were fairly good and 2 were of the opinion that it was poor. The pharmacy rating was evaluated as good by 32 (29.09\%), fairly good by 78 $(70.90 \%)$ and no respondents were of opinion that the pharmacy was poor in its service. Through this study, we found that the overall perception of patients towards the pharmacist in concerned community pharmacy setting was good. To further improvise their role, continued pharmacy education programmes, better communication skills and good professional training must be imparted among the community pharmacists.
\end{abstract}

KEYWORDS: Pharmacist, Community Pharmacy, Over The Counter Drugs, Medication, Patient's Perception

\section{INTRODUCTION}

Pharmacists are trusted and highly accessible professionals. With their knowledge of disease and medications, pharmacists are in the position to assist the health providers with better management and monitoring of disease and medication use. Pharmacists will be able to determine conditions appropriate for self care versus physical referral. Ultimately, routine patient assessment performed by pharmacists can lead to better patient outcomes [1]. Over the past four decades there has been a trend for pharmacy practice to move away from it's original focus on medicine supply towards a more inclusive focus on patient care. The role of the pharmacist has evolved from that of a compounder and supplier of pharmaceutical products towards that of a provider of services and information and ultimately that of a provider of patient care [2]. Increasingly, the pharmacist's task is to ensure that a patient's drug therapy is appropriately indicated, the most effective available, the safest possible, and convenient for the patient. By taking direct responsibility for individual patient's medicine-related needs, pharmacists can make a unique contribution to the outcome of drug therapy and to their patient's quality of life [3].

Pharmacists need to ensure that people can access medicines or pharmaceutical advice easily and, as far as possible, in a way and at a time and place of their own choosing. They can empower patients by engaging them in dialogue to communicate knowledge which enables them to manage their

Copyright: $\odot$ The authors. This article is open access and licensed under the terms of the Creative Commons Attribution License (http://creativecommons.org/licenses/by/4.0/) which permits unrestricted, use, distribution and reproduction in any medium, or format for any purpose, even commercially provided the work is properly cited. Attribution - You must give appropriate credit, provide a link to the license, and indicate if changes were made. 
own health and treatment [4]. Although patients are exposed to a wide range of information from package inserts, promotional materials, advertising in the media and through the internet, this information is not always accurate or complete [4,5]. The pharmacist can help informed patients to become accurately informed patients by offering unbiased relevant evidence-based information and by pointing to reliable sources [5]. Counselling on disease prevention and lifestyle modification will promote public health, while shared decision-making on how to take medicines through a concordant approach will optimize health outcomes, reduce the number of medicine-related adverse events, cut the amount of medicine which is wasted and improve adherence to medication [6]. As the experts in medicines, pharmacists have always been known as an accessible and trusted source of advice and treatment. Today, their contribution to health care is developing in new ways to support patients in their use of medicines and as a part of clinical decision-making across the range of specialisms [7].

Pharmacies are open all day, are convenient for most people to get to and there is no need for an appointment to see the pharmacist. All this makes pharmacies the natural first port of call for help with common ailments. Self-treatment of common ailments is becoming more popular as a growing range of safe, effective medicines becomes available from the pharmacy without the need for a doctor's prescription. Pharmacists have the expertise to advise both on the choice of medicines and their safe and effective use $[7,8]$. The right choice of self-treatment can prevent some conditions from developing or help others clears up more quickly. The term "clinical pharmacy" was coined to describe the work of pharmacists whose primary job is to interact with the health care team, interview and assess patients, make specific therapeutic recommendations, monitor patient responses to drug therapy and provide medicines information [9].

The health care team consists of the patient and all the health care professionals who have responsibility for patient care. This team needs to be well defined, and collaboration needs to be actively sought. Pharmacists have an important role to play in this team. They will need to adapt their knowledge, skills and attitudes to this new role, which integrates traditional pharmaceutical science with clinical aspects of patient care, clinical skills, management and communication skills, active collaboration with medical teams and solving of medicine-related problems [10]. If they are to be recognized as full members of the health care team, pharmacists will need to adopt the essential attitudes required by health professionals working in this area: visibility, responsibility, accessibility in a practice aimed at the general population, commitment to confidentiality and patient orientation. Pharmacists will need to be competent and possess both vision and a voice to fully integrate themselves into the health care team [11]. The role of the pharmacist takes different forms in various parts of the world. The pharmacist's involvement with pharmaceuticals can be in research and development, formulation, manufacturing, quality assurance, licensing, marketing, distribution, storage, supply, information management, dispensing, monitoring or education. Supply and information management activities have been termed "pharmaceutical services" and continue to form the foundation of pharmacy practice [12]. Pharmacists practice in a wide variety of settings. These include community pharmacy (in retail and other health care settings), hospital pharmacy (in all types of hospital from small local hospitals to large teaching hospitals), the pharmaceutical industry and academics. Pharmaceutical care concept is received by the pharmacists around the world. The community pharmacists are the most accessible health care professionals to the public [13]. They provide health/medical facilities and dispense medicines in accordance with legal and ethical permission, either on prescription or as over the counter (OTC) medicines. They also bridge the gap between doctors and patients for optimal and rational use in the medicines. The community pharmacist perform a variety of functions including procurement and dispensing of drugs, patient counselling and education, health promotion, drug information and consultation services to the health care professionals on the rational selection of medicines [14].

In some developed countries, the pharmacists are rated as one of the top professionals who serve the society. This recognition to pharmacist is due to the professional services rendered by them to improve the public health in the community [15]. Pharmacist in developed countries working in hospitals and community providing pharmaceutical care services to these patients to improve the quality of life. Patient counselling is considered as an important component of pharmaceutical care services. In most of the developed countries, patient counselling is regarded as an important professional responsibility of pharmacists and in some countries it is also found to be mandatory [16]. United States pharmacopoeia has identified and listed barriers for counselling in community pharmacies. One of the important barriers of counselling are provider based, i.e. the pharmacists. Lack of knowledge, lack of time, lack of training, lack of interest, lack of remuneration are the important reasons expressed by pharmacist in some international studies [17].

In India there are 0.6 million pharmacists serving in the community. Most of them are with basic qualification, Diploma in pharmacy (D.pharm). Majority of the practising pharmacists are confined to trade activation in the community and engage only in filling the prescription. Some pharmacists may provide medication information to the patients only on request. In India, the community pharmacy practice is different [18]. The community pharmacies are generally called as medical stores, drug store, or chemist shop. As per section 42 of 1948 pharmacy act, only qualified persons are permitted to sell the pharmaceutical formulations. In order to induce the professional competency, Pharmacy Council of India (PCI) introduced educational regulations in 1953 for standardising Diploma in pharmacy education [19]. Many changes were brought in curriculum of Diploma in pharmacy over the five decades. Despite of efforts by statutory bodies, registration and regulatory authorities, pharmacists in community pharmacies are still confined themselves to trade than blending the trade with profession. Many pharmacists are unaware of their professional role and responsibilities. The pharmacy profession was pursuing an extended role for pharmacist in primary health care. Pharmaceutical care is the responsible 
provision of drug therapy for the purpose of achieving definite outcomes that improve a patient's quality of life $[20,21]$. The American pharmacists association defines pharmaceutical care as "patient centred, outcome oriented pharmacy that requires the pharmacist to work in concert with the patient and the patient's other health care providers to promote health, to prevent diseases and to assess, monitor, initiate and modify medication use to assure that drug therapy regimen are safe and effective" [22]. Both definitions indicate that pharmaceutical care is a form of pharmacy practice that is patient centred, rather than medication centred, requiring pharmacist to accept responsibility as direct patient care provider. India is a country with significant drug related problems due to polypharmacy such as drug duplication, under dose, over dose, potential drug interaction, illiteracy, inadequate information about medication usage [23]. Due to heavy patients load, doctors consultancy limits to the issue of prescription to patients with very limited or no information about medications and their use. Pharmacists who are supposed to be the information providers and should act as vital link between patient and prescribers are remaining as the prescription fillers. The broad availability of drugs without prescription is found in countries like gulf, Central America, parts of Eastern Europe and Asia with the exception of antibiotics, anabolic steroids, narcotics and controlled drugs. Patient self medication may also unwittingly generate dangerous drug-drug and drug-disease interaction [24]. The wide range of non-prescription medicines highlights the need for professional guidance. Pharmacist play a valuable role in identifying, solving and preventing drug related problems (DRPs) for the purpose of achieving optimal patient care [25]. This study acts as a baseline source to assess the perception of a pharmacist in community pharmacy settings in north Malabar region of Kerala, India.

\section{METHODOLOGY}

A questionnaire based survey on patient's perception of community pharmacist in north Malabar region of Kerala was conducted between September 2019 to December 2019. We used a questionnaire with multiple choice questions to obtain our data, which were answered by patients during his/her visit to community pharmacy. The questionnaire was developed based on a survey carried out in Pharmacy Practice Research Resource Centre, Manchester, with suggestion made by the professionals of our institution based on various literature sources referred $[26,27,28]$. Data were collected by face to face structured interview of respondents in the community pharmacy, explaining them that it was voluntary and confidential. The questionnaire used for data collection consisted of two sections with a total of 16 questions. The first section included questions on person's descriptive characteristics (age, sex, marital status, education level \& occupation). The second section included questions on perception of patients towards the community pharmacist such as role of pharmacist in community setting, advice provided by the pharmacist on general health issues, recommendations made by pharmacist, information provided by the pharmacist prior to dispensing of medication, overall rating of the pharmacy and pharmacist services. The attitude and perception were measured based on the questionnaire with statements and three point likert scale ratings. The duly filled questionnaires were collected and were further coded in Microsoft Excel 2013 version. The descriptive statistics were used for data analysis. The results were based upon data captured from 110 patients. The patient's perception was reported as percentages.

\section{RESULTS}

Of the 135 questionnaire distributed, 110 (81.48\%) were answered and the rest were probably ignored by the patients.

\section{Patient Sociodemographic Characteristics}

The sociodemographic features of respondents are shown in Table 1. Approximately 51 (46.36\%) were adults (18-59 years), and $59(53.63 \%$ ) were geriatrics (above 60 years). Education level of patients in study were 9 illiterates $(8.18 \%), 35$ with secondary education (31.81\%) and 66 graduates (60\%). Respondents of study were found to be 73 males $(66.36 \%)$, and 37 females $(33.63 \%)$.

\section{Patient's Purpose of Visiting Community Pharmacy}

Among 110 respondents, the majority of patients visited the pharmacy to get their prescription dispensed (66, 60\%). 28 patients $(25.45 \%)$ visited the pharmacy in order to buy an over the counter (OTC) medicine. 10 patients (09.09\%) visited the pharmacy for non-medical goods. But, only 6 patients $(05.45 \%)$ met the pharmacist to get advice on general health.

\section{Patient's Perception of Community Pharmacist}

Facts from study suggest that 94 out of 110 patients were aware of pharmacist necessity in pharmacy. 45 out of 110 patients were aware of their medication. The patient knowledge level regarding their disease condition and the role of pharmacist in a community setting is shown in Table 2 . It was found that $85(77.27 \%)$ were aware and $25(22.72 \%)$ were unaware about their disease condition. From the view point of study, it was also found that prior to dispensing, the pharmacist enquired about herbal medication (31), medication history (58) and allergy (21). Advice regarding dosage (90\%), side effects (25\%), storage $(12 \%)$, healthy eating \& exercise $(10 \%)$ were provided to patients by the pharmacist (Table 3$)$. The studies, to a

Table 1: The sociodemographic features of the respondents of the study $(n=110)$

\begin{tabular}{lcc}
\hline Characteristic feature & $\mathrm{n}$ & $\%$ \\
\hline Gender & & \\
$\quad$ Male & 73 & 66.36 \\
$\quad$ Female & 37 & 33.64 \\
Age distribution & & \\
$\quad$ Adults & 41 & 37.27 \\
$\quad$ Geriatrics & 69 & 62.73 \\
Education level & & \\
$\quad$ Illiterate & 9 & 8.18 \\
$\quad$ Secondary education & 35 & 31.82 \\
Graduates & 66 & 60.00 \\
\hline
\end{tabular}




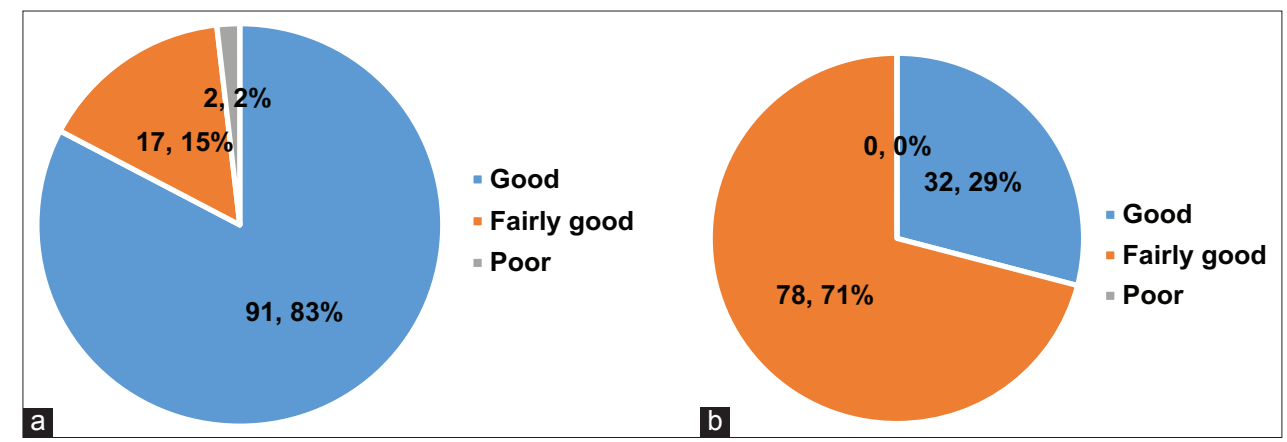

Figure 1: a) Patient's opinion regarding the community pharmacist, and b) the pharmacy rating given by patients

Table 2: The knowledge level of respondents regarding their disease condition and importance of a community pharmacist

\begin{tabular}{lcc}
\hline Item & $\mathrm{n}$ & $\%$ \\
\hline 1. Whether the study group aware of 'pharmacist' necessity in a pharmacy? \\
Yes & 94 & 85.45 \\
No & 16 & 14.55 \\
2. Patient knowledge regarding their medication & & \\
$\quad$ Aware & 45 & 40.91 \\
Unaware & 65 & 59.09 \\
3. Patient knowledge regarding their disease condition & & \\
$\quad$ Aware & 85 & 77.27 \\
Unaware & 25 & 22.73 \\
\hline
\end{tabular}

Table 3: The pharmacist's attitude towards the patient

\begin{tabular}{lcc}
\hline Item & $\mathrm{n}$ & $\%$ \\
\hline 1. Enquiry and clarification given by pharmacist prior to dispensing \\
regarding - & 31 & 28.18 \\
Herbal medication & 58 & 52.73 \\
Past medication history & 21 & 19.09 \\
Allergic conditions & 72 & 65.45 \\
2. Advice or councelling given by the pharmacist regarding - & \\
Dosage & 18 & 16.36 \\
Side effects & 11 & 10.00 \\
Storage & 9 & 8.18 \\
Healthy eating \& exercise & & \\
\hline
\end{tabular}

considerable extent, were helpful in evaluating the performance of pharmacist in community pharmacy. 91 out of 110 patients thought the pharmacist service were good, 17 thought they were fairly good and 2 were of the opinion that it was poor. The pharmacy rating was evaluated as good by $32(29.09 \%)$, fairly good by $78(70.90 \%)$ and no respondents were of opinion that the pharmacy was poor in its service (Figure 1).

\section{DISCUSSION}

The aim of the study was to assess patient's perception of community pharmacist and pharmaceutical care. Many surveys have found that community pharmacies are very often the first and only source of health care out side the home. Increase in attention is now being paid for the patient satisfaction, although the patient background characteristics are among the most difficult to relate the level of satisfaction. A large percentage of the patients were unaware about the need of pharmacist in a pharmacy and most of them considered the pharmacist as a sales person. The community pharmacist should demonstrate his/her increased skill and actively participate in health care service, so that they can have a distinguished recognition in the community. It is interesting to note that most of the patients are not aware about the type of medicines that was provided by the physician and also about their disease/disease condition. Although the patients would likely to know about these condition, the pharmacist appear to be unapproachable, being busy with prescription dispensing or do not give importance to provide these type of information. In this study, the patients have generally rated the services provided by the pharmacist poorly. Specific information on medication and other health related problems including side effects, dosage, directions, storage, etc that can enhance medication therapy were hardly discussed with the patients. An important finding in the study was that pharmacist rarely enquired about past medication history and drug allergy from the patients, prior to dispensing the medication. However lack of time was the problem found by the most of pharmacist, which was mainly due to the lack of man power. This study has also highlighted some of the aspects of pharmacy important services to patients and considered fundamentally to the development of strategy to expand and promote community pharmacy services. Advancing community pharmacy services will increase expectation of patients. One of the studies on the effect of a continuous community pharmacy practise was beneficial for all students and practising pharmacist. Community pharmacist had more direct access to patients and so the counselling was more effective. To be effective in this role, the pharmacist need to have good professional training and improving his communication skills by devoting more of his time for these activities.

\section{CONCLUSION}

The patient's perception of community pharmacist in north Malabar region of Kerala is high. This could reflect the trends in all the Kerala state. The most beneficial pharmaceutical care offered to patients in community pharmacy are advise given about medication and on general health issues. The result of the study showed a high level of public support for the advisory role of the pharmacist. Although the image of pharmacist as a health promoter is only partially influenced by the public. Furthermore a variety of other factors that motivate pharmacy visits were also determined. Finally, it is not possible to conclude from the present study the reasons that inhibit the urge of pharmacist for giving counselling to patients. Though the 
study was successful in evaluating the perception of community pharmacist, there is a need for research in this area, involving more number of study group so as to extrapolate our findings. This study reveals the need to carry out continuing pharmacy education program to help them in improving their knowledge. For that it is paramount to have an active participation of all community pharmacists.

\section{REFERENCES}

1. Ford RC, Bach SA, Fottler MD. Methods of measuring patient satisfaction in health care organizations. Health Care Management Review. 1997;22:74-89.

2. Hepler CD, Strand LM. Opportunities and responsibilities in pharmaceutical care. American Journal of Hospital Pharmacy. 1990;47:533-543.

3. Aguwa CN. Therapeutic Basis of Clinical Pharmacy in theTropics. 3rd ed. Enugu, Nigeria:SNAAP Press Limited:2004.

4. Erah PO, Bafor EE. Assessment of pharmacist patient communication in some health care Facilities in southern Nigeria. Nigerian Journal of Pharmaceutical Sciences. 2004;3:23-34.

5. Chen K, Chiou CF, Plauschinat CA, Frech F, Harpera DR. Patient satisfaction with antihypertensive therapy. Journal of Human Hypertension. 2005; 19:793-799.

6. Wazaify M, Al Bsoul Younes S, Abu Gharbieh E, Tahaineh L. Social perspectives on role of community pharmacists and OTC. Pharmacy World and Science. 2008;30:884-891.

7. Castle NG, Hanlon JT, Handler SM. Whom do older adults trust most to provide information about prescription drugs? American Journal of Geriatric Pharmacotherapy. 2009;7:105-116.

8. Courtenay M. Nursing prescribing, policy, practice and evidence base. British Journal of Community Nursing. 2008;13:563-566.

9. Hansford D, Gill D, McLaren J, Krska J. A training package for primary care nurses in conducting medication review: their views and the resultant outputs. Journal of Clinical Nursing. 2009;18:1096-1104.

10. Nau DP. A perceived value framework for explaining patients intension to use pharmaceutical Care Services. M.pharm Thesis in Pharmacy practice to University of Florida;1997.

11. Oparah CA, Iwuagwu MA. Public perception of community pharmacists in Benin City, Nigeria. International Journal of Pharmacy Practice. 2001;9:191-195.

12. Staessen JA, O'Brien ET, Thijs L, Fagard RH. Modern approaches to blood pressure measurement. Occupational Environmental Medicine. 2000;57:510-520

13. Selenta C, Hogan BE, Linden W. How often do office blood pressure measurements fail to identify true hypertension? Archives of Family Medicine. 2000;9:533-540.

14. Jaylett M. Ambulatory or self blood pressure measurement, improving the diagnosis of hypertension. Family Practice.1994;11:197-200.

15. Donabedian A. Defining and measuring the quality of health care Assessing Quality Health Care. Perspectives for Clinicians. $4^{\text {th }}$ ed. Baltimore:Williams and Wilkins:1992.

16. Rosenthal GE, Shannon SE. The use of patient perceptions in the evaluation of health care delivery systems. Medical Care. 1997;35:58-68.

17. Ware J, Hayes R. Methods for measuring patient satisfaction with specific medical encounters. Medical Care. 1988;26:393-402.

18. Pascoe G. Patient satisfaction in primary healthcare: a literature review and analysis. Evaluation and Program Planning. 1983;6:185-210.

19. Rubin H. Can patients evaluate the quality of hospital care? Medical Care Review. 1990; 47:267-326.

20. Donabedian A. The role of outcomes in quality assessment and assurance. Quality Review Bulletin. 1992;18:356-360.

21. Calnan MW. Lay evaluation of medicine and medical practice: report of a pilot study. International Journal of Health Service. 1988; 18:311-322.

22. Calnan MW. The patient's perspective. International Journal of Technology Assessment in Health Care. 1998;14:24-34

23. Amery A, Birkenhager W, Brixko P, Bulpitt C, Clement D, Deruyttere M, De Schaepdryver A, Dollery C, Fagard R, Forette F, Forte J, Hamdy R, Henry JF, Joossens JV, Leonetti G, Lund Johanssen P, O'malley K, Petrie J, Trasser T, Tuomilehto J, Williams BI. Mortality and morbidity results from the European working party on high blood pressure in the elderly trial. Lancet. 1985;1:1349-1354.

24. Luscher TF, Vetter H, Slegenthaler W, Vetter W. Compliance in hypertension: facts and concepts. Journal of Hypertension. 1985;3:3-9.

25. Federal Ministry of Health, Nigeria (FMOH). Non communicable diseases in Nigeria: Final report of a national survey by the National Expert Committee on Non-Communicable diseases; 1997

26. McEnteea JE, Hendersona SL, Rutterb PM, Ruttera J, Davisa HJ. Utility and value of a medicines information service provided by pharmacists: a survey of health professionals. 2010;18:353-361.

27. Catic T, Jusufovic Fl, Tabakovic V. Patients Perception of Community Pharmacist in Bosnia and Herzegovina. Materia Socio Medica. 2013;25:206-209.

28. Gelayee DA, Mekonnen GB. Perception of Community Pharmacists towards Dispensing Errors in Community Pharmacy Setting in Gondar Town, Northwest Ethiopia. BioMed Research International. 2017;1:1-9. 